ARTICLE

https://doi.org/10.1038/s41467-019-10882-x

\title{
Engineering transkingdom signalling in plants to control gene expression in rhizosphere bacteria
}

\author{
Barney A. Geddes (10) 1,5, Ponraj Paramasivan (10) 2,5, Amelie Joffrin (1) 3,5, Amber L. Thompson (1) ${ }^{3}$, \\ Kirsten Christensen (1) ${ }^{3}$, Beatriz Jorrin (1) 1, Paul Brett ${ }^{4}$, Stuart J. Conway (1) ${ }^{3,6}$, Giles E.D. Oldroyd (1) ${ }^{2,6} \&$ \\ Philip S. Poole (10) 1,6
}

The root microbiota is critical for agricultural yield, with growth-promoting bacteria able to solubilise phosphate, produce plant growth hormones, antagonise pathogens and fix $\mathrm{N}_{2}$. Plants control the microorganisms in their immediate environment and this is at least in part through direct selection, the immune system, and interactions with other microorganisms. Considering the importance of the root microbiota for crop yields it is attractive to artificially regulate this environment to optimise agricultural productivity. Towards this aim we express a synthetic pathway for the production of the rhizopine scyllo-inosamine in plants. We demonstrate the production of this bacterial derived signal in both Medicago truncatula and barley and show its perception by rhizosphere bacteria, containing bioluminescent and fluorescent biosensors. This study lays the groundwork for synthetic signalling networks between plants and bacteria, allowing the targeted regulation of bacterial gene expression in the rhizosphere for delivery of useful functions to plants.

\footnotetext{
${ }^{1}$ Department of Plant Sciences, University of Oxford, South Parks Road, Oxford OX1 3RB, UK. ${ }^{2}$ Sainsbury Laboratory, University of Cambridge, Bateman Street, Cambridge CB2 1LR, UK. ${ }^{3}$ Chemistry Research Laboratory, Department of Chemistry, University of Oxford, Mansfield Road, Oxford OX1 3TA, UK. ${ }^{4}$ Department of Metabolic Biology, John Innes Centre, Norwich Research Park, Norwich NR4 7UH, UK. ${ }^{5}$ These authors contributed equally: Barney A. Geddes, Ponraj Paramasivan, Amelie Joffrin. ${ }^{6}$ These authors jointly supervised this work: Stuart J. Conway, Giles E.D. Oldroyd, Philip S. Poole. Correspondence and requests for materials should be addressed to P.S.P. (email: philip.poole@plants.ox.ac.uk)
} 
T he root microbiota, like the gut microbiota in human health, is critical for plant health and agricultural yield ${ }^{1,2}$. It is shaped by plant selection ${ }^{3,4}$ and its immune system ${ }^{5}$, as well as complex interactions between microorganisms. Plant growthpromoting bacteria can alter nutrient availability and antagonise pathogens. Perhaps, the most important plant-microbe interaction is between legume plants and symbiotic bacteria called rhizobia. Natural transkingdom signalling between them is essential for the establishment of rhizobia in plant root organs called nodules. In root nodules rhizobia reduce atmospheric $\mathrm{N}_{2}$ to ammonia, producing a substantial proportion of the biosphere's available nitrogen.

The root microbiota represents an enormous potential for improving crop yields by engineering the plant microbiome. Enhancing crop productivity in a sustainable manner may be achieved in several ways, including transfer of bacterial $\mathrm{N}_{2}$ fixation to cereals ${ }^{6-9}$, harnessing bacterial phosphate solubilisation, promoting root growth by bacterial synthesis of plant hormones, or pathogen antagonism by antibiotic production. These plant growth-promoting services by bacteria could be regulated by engineering plants to produce a synthetic transkingdom signal to control bacteria on roots. Such a signal must be: (1) amenable to engineering in plants, (2) able to elicit a bacterial response, (3) exuded into the rhizosphere (zone of soil surrounding the roots) and (4) not normally be made by plants. Transgenic plants that produced opine molecules, repurposed from Agrobacterium, have been shown to enrich their rhizosphere with bacteria able to catabolize opines; however, utilizing a nutritional mediator of pathogenic organisms as a signal is undesirable ${ }^{10-12}$. A group of compounds, called rhizopines, were recognised as ideal chemical signals, although efforts to engineer rhizopine-producing plants in the past were unsuccessful ${ }^{13}$. Rhizopines (scyllo-inosamine 1 (SIA) and 3-O-methyl-scyllo-inosamine 2 (3-O-MSI)) (Fig. 1a) are synthesised by a few species of rhizobia in legume nodules, under the control of the NifA regulator, during $\mathrm{N}_{2}$-fixing symbiosis $^{14}$. These molecules are rare in nature ${ }^{15}$ and absent from most plant rhizospheres. Rhizobia are able to synthesise rhizopines and utilise them as carbon and nitrogen sources. Genes involved in the biosynthesis $(\operatorname{mos} A B C)$ and catabolism of rhizopines (mocCABRDEF) have been identified in the wild-type rhizobium Sinorhizobium meliloti L5-30 ${ }^{16,17}$. Although the natural role of rhizopines remains to be elucidated, previous studies suggested that they may be exuded into the rhizosphere ${ }^{14,18}$.

In this study, we demonstrate the exudation of rhizopines into the rhizosphere by a rhizobium-legume symbiosis and elucidate the biochemical pathway for 3-O-MSI 2 biosynthesis by rhizobia in legume nodules. We show that while the 3-O-MSI 2 biosynthetic pathway is not readily amenable to transfer to plants, the biosynthesis of the rhizopine SIA $\mathbf{1}$ is. Finally, we establish synthetic SIA-mediated transkingdom signalling from transgenic Medicago truncatula and barley plants to bacteria in their rhizospheres.

\section{Results}

Rhizopine exudation during rhizobial symbiosis. To validate rhizopines as targets for transkingdom signalling, we first wished to confirm they are exuded into the plant rhizosphere in their natural context (synthesis by rhizobia in $\mathrm{N}_{2}$-fixing root nodules). To investigate exudation into the rhizosphere, a rhizopine biosensor (pOPS0046) was made by cloning the mocB promoter (encodes a putative ATP transporter substrate-binding protein in the rhizopine catabolism locus) and its divergent regulator mock ${ }^{19}$ into a lux reporter vector ${ }^{20}$. Exudation of rhizopine into the rhizosphere was measured by bacterial luminescence on roots $^{20}$ of the natural host of $S$. meliloti L5-30, Medicago sativa.
Plants were co-inoculated with S. meliloti L5-30 (which nodulates and produces rhizopine) and Rhizobium leguminosarum (Rlv3841) carrying pOPS0046 (contains the biosensor but cannot nodulate). Medicago sativa plants nodulated by S. meliloti L5-30 caused bioreporter Rlv3841 to bioluminesce on the root surface adjacent to nodules (Fig. 1b, Supplementary Fig. 1), confirming rhizopines traverse plant tissues to reach the root surface.

To confirm that the biosensor responds specifically to rhizopines, SIA 1 was obtained via a revised synthetic route, and both enantiomers of 3-O-MSI, (-)-1L-2 and (+)-1D-2, were synthesised using a protection-resolution strategy (Supplementary Figs. 2 and 3). The absolute configuration of key synthetic intermediates was confirmed by nuclear magnetic resonance analysis (Supplementary Table 5) and single-crystal X-ray diffraction. Induction of the biosensor was tested in free-living culture in response to SIA 1, (-)-1L-3-O-MSI (-)-1L-2 and $(+)-1 \mathrm{D}-3-O-M S I(+)-1 \mathrm{D}-2$, and the naturally abundant cyclitols myo-inositol 3, (+)-1D-ononitol (+)-1D-4 and (+)-1D-pinitol (+)-1D-5 (Fig. 1a). The biosensor was activated by SIA 1 and (-)-1L-3-O-MSI (-)-1L-2 (Fig. 1c, d). (-)-1L-3-O-MSI (-)-1L-2 has previously been proposed to be the naturally occurring enantiomer ${ }^{21}$, and the preference for this enantiomer observed in Fig. 1c, d supports this. Furthermore, (-)-1L-3-O-MSI (-)-1L-2 promoted the growth of S. meliloti L5-30, whereas (+)-1D-3-OMSI (+)-1D-2 did not (Supplementary Fig. 4), supporting results from a recent study ${ }^{21}$. The confirmation of the chemical structure of rhizopines, and their secretion into the rhizosphere, provides a unique opportunity to use them as target molecules for engineering plant control of root bacteria.

Elucidation of the natural 3-O-MSI biosynthetic pathway. In $S$. meliloti L5-30 the genes mos $A B C$ were proposed to encode the pathway for 3-O-MSI biosynthesis ${ }^{13,17}$. MosA was thought to be a methyltransferase ${ }^{22}$, while MosB and MosC are homologous to aminotransferase and transmembrane transport proteins, respectively ${ }^{13,16}$. However, rhizopines were not produced when mos $A B C$ was expressed in Arabidopsis thaliana ${ }^{13}$. Furthermore, the role of MosA in 3-O-MSI synthesis has been questioned ${ }^{23}$, suggesting mos $A B C$ may not encode the complete rhizopine pathway. Bioinformatic analysis of rhizobial genomes indicated that mos $A$ is not widely distributed among putative rhizopine loci (Supplementary Fig. 5). In addition, three genes, which we name mosDEF, were found downstream of mosC in many putative rhizopine loci. Comparative analytical chemistry by gas chromatography-mass spectrometry (GC-MS), using nodule extracts from several of these rhizobia and chemically synthesised $( \pm)$-3-O-MSI $( \pm)$-2 as a standard, revealed that mosBCDEF are present in all rhizobia that synthesised 3-O-MSI (Supplementary Fig. 5).

Supporting the role of mosDEF in 3-O-MSI synthesis, a $S$. meliloti L5-30 strain disrupted in mosE showed no detectable rhizopine synthesis in nodules (Fig. 2a). Based on homology, MosDEF is likely to be a membrane-bound flavin adenine dinucleotide-dependent dehydrogenase comple ${ }^{24}$. We hypothesized that the dehydrogenase complex, MosDEF, oxidises (+)-1Dononitol (+)-1D-4 at the axial C-2 hydroxyl group to form 3-Omethyl-scyllo-inosose 1D-6. This keto-inositol intermediate could undergo reductive amination catalysed by MosB to generate $(-)-1 \mathrm{~L}-3-O-M S I(-)-1 \mathrm{~L}-2$.

To test this hypothesis, mosDEF was expressed in S. meliloti Rm1021 nodules (strain that does not produce rhizopines) and a compound accumulated that had an identical retention time and mass spectrum to a peak that eluted immediately before $(+)$-1D-ononitol $(+)-1 \mathrm{D}-4$ in nodules produced by wild-type S. meliloti L5-30, but not in $\operatorname{mos} E$ or $\operatorname{mos} B$ mutants (Fig. 2a, b). 
a

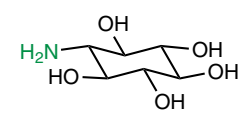

SIA 1

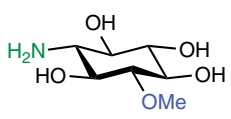

$(-)-1 \mathrm{~L}-3-O-M S I(-)-1 \mathrm{~L}-2$

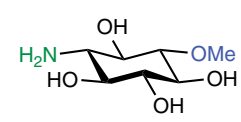

(+)-1D-3-O-MSI (+)-1D-2

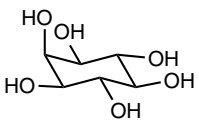

myo-inositol 3

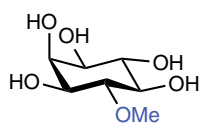

(+)-1D-Ononitol (+)-1D-4

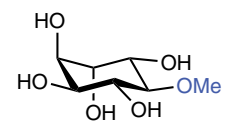

(+)-1D-Pinitol 5

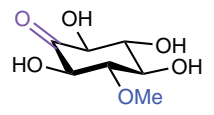

1D-3-O-MSO 1D-6

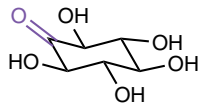

scyllo-inosose 7

b

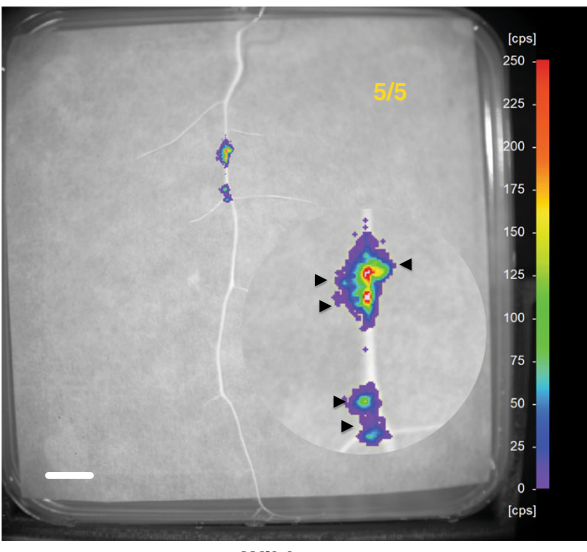

Wild type

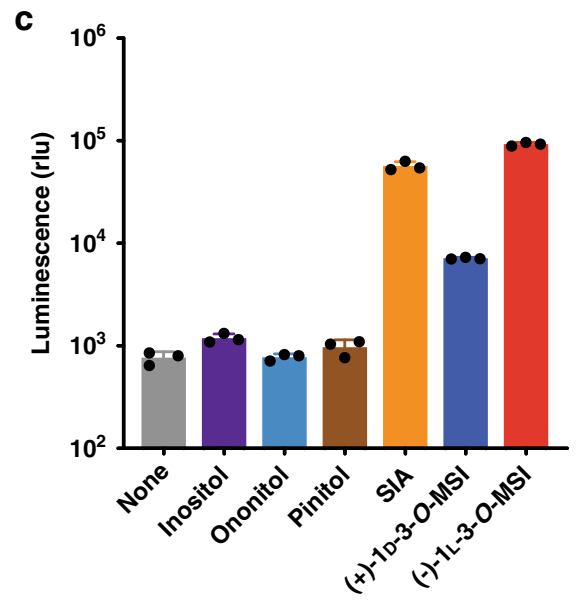

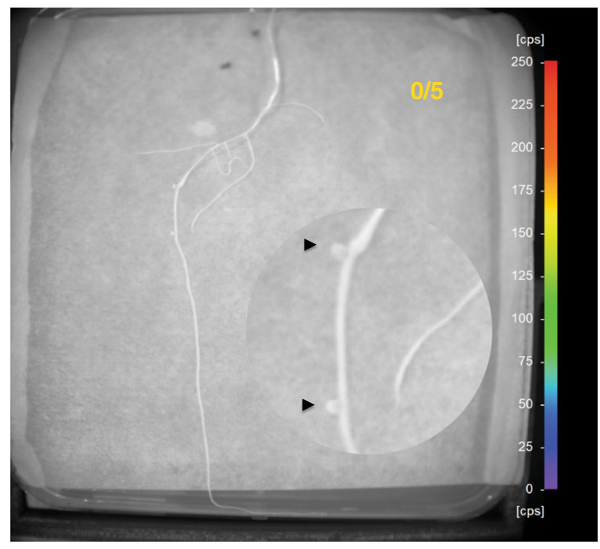

$\operatorname{mos} B$

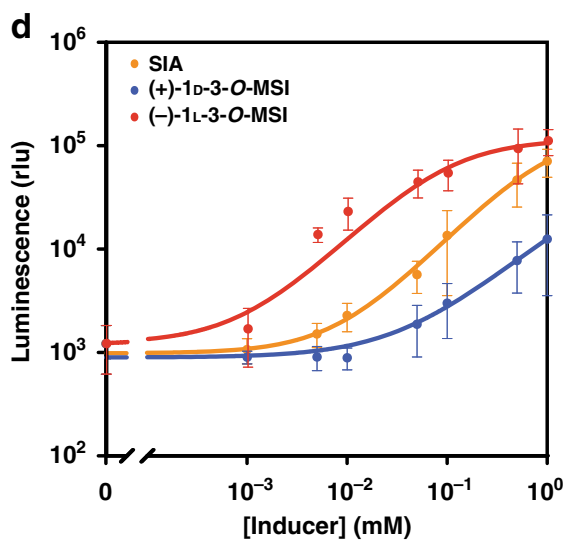

Fig. 1 Detection of rhizopine exudation with a rhizopine biosensor. a Chemical structures of rhizopines and related cyclitols. b NightOwl images of bioluminescence of $R$. leguminosarum Rlv3841/pOPS0046 rhizopine lux biosensor on the surface of $M$. sativa roots nodulated by S. meliloti L5-30 wild-type (rhizopine+) and S. meliloti L5-30 mosB:pK19 (rhizopine -, see Fig. 2a). Numbers in top right corners indicate number of plants tested that showed significant levels of bioluminescence $(n=5)$. Circle in bottom right corner contains magnified image of a root section enriched with nodules. The positions of nodules are indicated with arrowheads (scale bar, $1 \mathrm{~cm}$ ). Colours represent luminescence intensity from 0 counts per second (cool/purple) to 250 counts per second (warm/red). c Specificity of induction of rhizopine lux biosensor with rhizopines compared to other chemically similar plant polyols, grown in UMS minimal medium with pyruvate and ammonia as carbon and nitrogen sources, supplemented with 1 mM of inducing molecule. Data are presented as relative luminescence units (rlu). Black dots indicate individual data points for each condition. $\mathbf{d}$ Induction curves showing the dynamic range and sensitivity of the rhizopine lux biosensor with chemically synthesised SIA 1, (-)-1L-3-O-MSI (-)-1L-2 and (+)-1D-3-O-MSI (+)-1D-2 grown in UMS minimal medium with pyruvate and ammonia as carbon and nitrogen sources. Error bars represent standard deviation of the mean of $n=3$ independent replicates. All experiments were repeated at least three independent times

We hypothesized that this compound was 3-O-methyl-scylloinosose 6. To identify this compound, ( \pm )-3-O-methyl-scylloinosose ( \pm )- 6 was synthesised to serve as a chemical standard in GC-MS experiments. Although chemically synthesised ( \pm )-3-Omethyl-scyllo-inosose $( \pm)-6$ was unstable in solution, following derivatisation and GC-MS analysis, a unique peak was observed with an identical retention time and mass spectrum to the compound produced in nodules formed by Rm1021 expressing $\operatorname{mos} D E F$ (Fig. 2b). This result is consistent with MosDEF being an ononitol dehydrogenase. Neither mosE nor mosB mutants appeared to accumulate ( \pm )-3-O-methyl-scyllo-inosose $( \pm)-6$, but both accumulated substantial amounts of $(+)-1 \mathrm{D}$-ononitol 

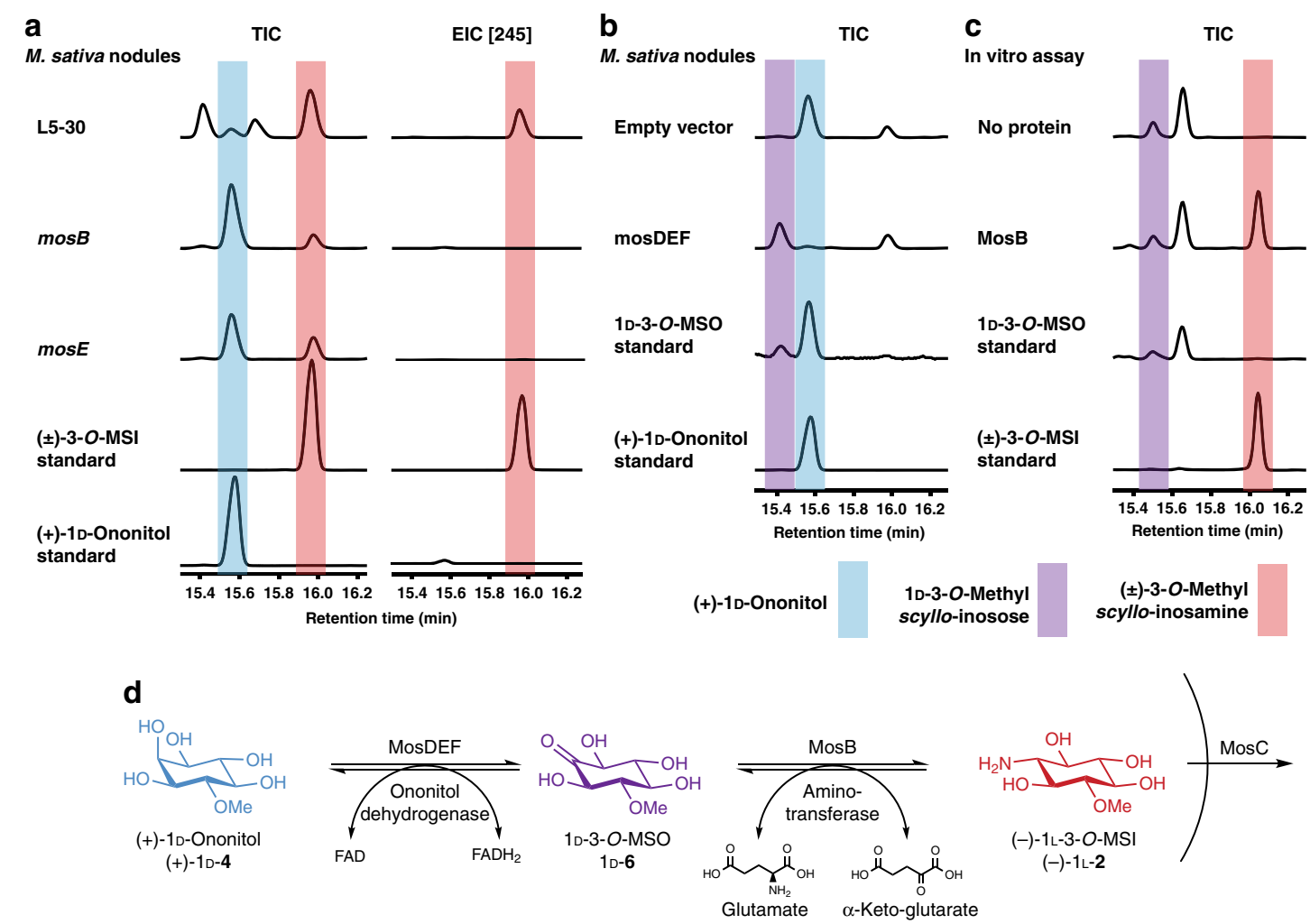

e
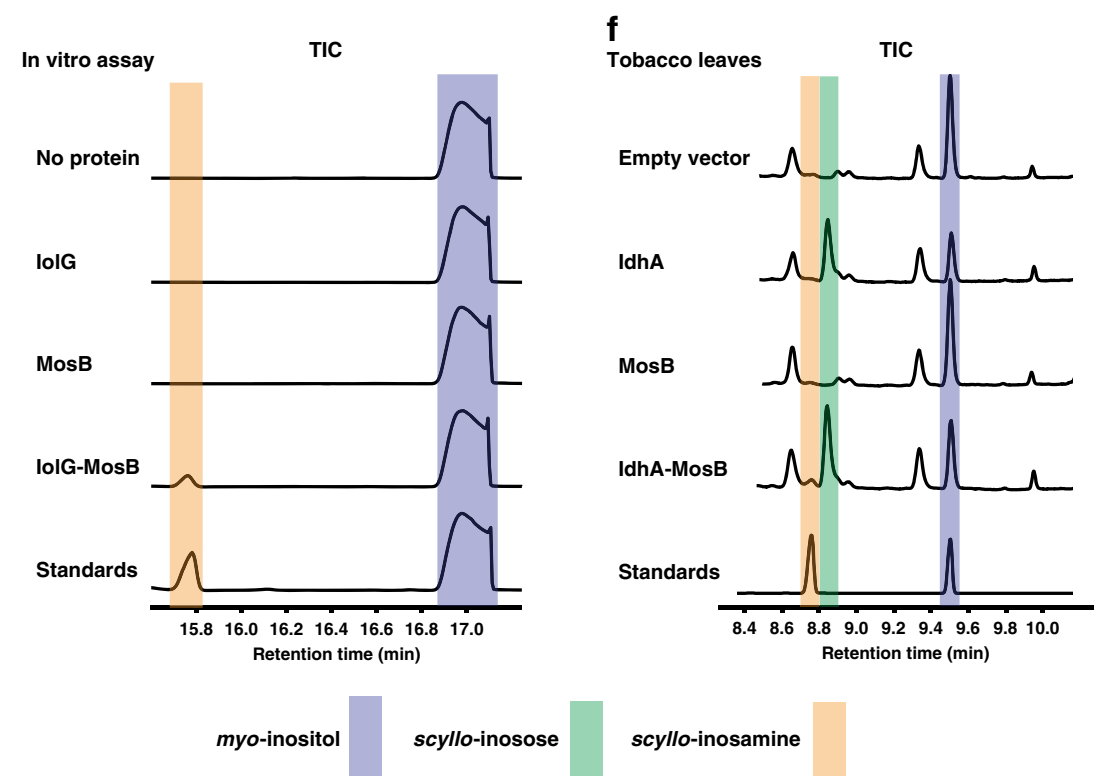

scyllo-inosamine

g

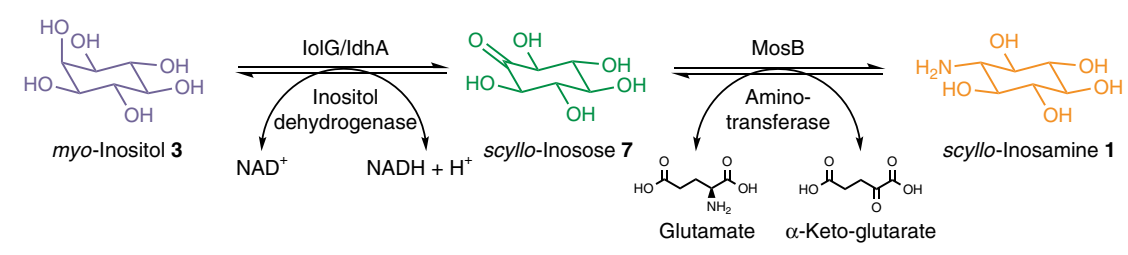

(+)-1D-4 (Fig. 2a). The absence of accumulation of ( \pm )-3-Omethyl-scyllo-inosose $( \pm)-6$ in $\operatorname{mos} E$ is predictable. However, its absence in $\operatorname{mos} B$ may be caused by spontaneous conversion to $(+)$-1D-ononitol (+)-1D-4, as observed in our chemical standard, or due to polarity of the $\operatorname{mos} B$ insertion mutation on mosDEF transcription.
Next, MosB was purified and when incubated with chemically synthesised 3-O-methyl-scyllo-inosose $( \pm)-6$, the cofactor pyridoxal 5'-phosphate (PLP), and L-glutamate, 3-O-MSI 2 was produced (Fig. 2c, Supplementary Fig. 6a). Therefore, MosB functions as a 3-O-methyl-scyllo-inosose: L-glutamate aminotransferase generating 3-O-MSI 2. 
Fig. 2 Discovery of a natural and synthetic pathway for rhizopine synthesis. a Gas chromatography-mass spectrometry (GC-MS) total ion chromatograms (TICs) (left) and extracted ion chromatograms ( $\mathrm{m} / \mathrm{z} 245=3-0-M S I-T M S)$ (EIC [245]) (right) of metabolites from nodules formed by wild-type S. meliloti L5-30 compared to mosB:pK19 and mosE:pK19 mutants. Chemically synthesised ( \pm )-3-O-MSI ( \pm )-2 and purchased (+)-1D-ononitol (+)-1D-4 as standards are shown below. $\mathbf{b}$ GC-MS chromatograms of metabolites from nodules formed by wild-type $S$. meliloti Rm1021 maintaining an empty vector (EV) and expressing mosDEF. Chemically synthesised ( \pm )-3-O-methyl-scyllo-inosose ( \pm )-6 and purchased (+)-1D-ononitol ( + )-1D-4 as standards are shown below. c GC-MS chromatograms (TIC) of MosB in vitro assay in the absence of protein or with MosB added. Chemically synthesised ( \pm )-3-0-methyl-scylloinosose ( \pm )-6 and ( \pm )-3-O-MSI ( \pm )-2 as standards are shown below. $\mathbf{d}$ Proposed natural pathway of 3-O-MSI biosynthesis in S. meliloti L5-30. e Linked in vitro assay of inositol dehydrogenase IoIG and MosB. GC-MS TICs of assay mix in the absence of added protein, with loIG added, with MosB added and with loIG and MosB added together. Standards represent a mix of SIA 1 and myo-inositol 3. $\mathbf{f}$ GC-MS TICs of extracts prepared from tobacco leaves agroinfiltrated with either empty vector (control) or IdhA or MosB or IdhA-MosB together. Standards represent a mix of SIA $\mathbf{1}$ and myo-inositol 3. $\mathbf{g}$ Proposed synthetic pathway of SIA 1 synthesis. Metabolites were identified by comparison with authentic standards. Highlighted peaks indicate scyllo-inosamine 1 (orange), scyllo-inosose 7 (green), myo-inositol 3 (dark blue), (+)-1D-ononitol 4 (light blue), 1D-3-O-methyl-scyllo-inosose $\mathbf{6}$ (purple) and (-)-1L-3-Omethyl-scyllo-inosamine $\mathbf{2}$ (3-O-MSI) (red). All chromatograms are representative of experiments repeated at least three independent times. Source data underlying $\mathbf{a}-\mathbf{c}$, e and $\mathbf{f}$ are provided as a Source Data file

Initial tests of 3-O-MSI synthesis in plants using Agrobacterium-mediated transient expression of McIMT (encodes myoinositol $O$-methyltransferase to produce $(+)-1 \mathrm{D}-$ ononitol $(+)-1 \mathrm{D}-$ 4 from myo-inositol 3), mosDEF and mosB together in Nicotiana benthamiana leaves did not yield 3-O-MSI 2 (Supplementary Fig. 7). MosDEF may need to interact with the bacterial membrane and/or the symbiotic bacterial electron transport chain to oxidise (+)-1D-ononitol (+)-1D-4 to 1D-3-O-methylscyllo-inosose 1D-6 (the substrate for MosB).

Engineering of SI biosynthesis in plants. To date, MosDEF is the only $(+)-1 \mathrm{D}$-ononitol dehydrogenase identified, making transfer of the natural pathway of 3-O-MSI synthesis to plants difficult; therefore, an alternative was sought. Since MosB uses 3O-methyl-scyllo-inosose $\mathbf{6}$ as the substrate backbone for transamination by L-glutamate, we considered that scyllo-inosose 7 (produced from myo-inositol 3 by bacterial inositol dehydrogenase ${ }^{25,26}$ ) may also act as a transamination substrate for MosB to generate SIA 1. IolG, the myo-inositol dehydrogenase from the Gram-positive bacterium Bacillus subtilis has been crystallized and the subject of extensive biochemical characterization $^{27-30}$, and we previously identified a myo-inositol dehydrogenase in the Gram-negative R. leguminosarum (IdhA) ${ }^{26}$. We tested both myo-inositol dehydrogenases for activity in plants and similar activity was observed for both iolG and idhA in N. benthamiana after transient infection (Supplementary Fig. 8). Following protein purification $B$. subtilis inositol dehydrogenase (IolG) showed higher activity in vitro (Supplementary Fig. 9), and was used in an in vitro assay of MosB scyllo-inosose: L-glutamate aminotransferase activity. While IolG showed robust enzyme activity in vitro, we were unable to observe scyllo-inosose 7 accumulation by GC-MS. We expect this was a result of instability of scyllo-inosose 7 in aqueous solutions, which we observed when we attempted its chemical synthesis. Nevertheless, when IolG was combined with MosB, myo-inositol 3 and $\mathrm{NAD}^{+}$ (substrate/cofactor for IolG), as well as L-glutamate and PLP, SIA 1 was only produced in the presence of both IolG and MosB (Fig. 2e, Supplementary Fig. 6b). Therefore, MosB also has scylloinosose: L-glutamate aminotransferase activity to generate SIA 1. In this synthetic pathway, bacterial inositol dehydrogenase oxidises myo-inositol 3 to scyllo-inosose 7 and MosB catalyses the glutamate transamination of 7 to generate SIA $\mathbf{1}$ (Fig. 2g). We expected this synthetic pathway to be amenable to transfer of SIA synthesis into plants.

To test whether this synthetic pathway is transferable to plants, inositol dehydrogenase from $R$. leguminosaurum (IdhA) and scyllo-inosose: L-glutamate aminotransferase (MosB) from $S$. meliloti were expressed in $N$. benthamiana leaves, and SIA 1 was produced (Fig. 2f, Supplementary Fig. 10). This represents the first successful transkingdom transfer of rhizopine (SIA) synthesis from bacteria to plants. Furthermore, it should enable control of members of the plant microbiota using the MocR regulator that responds to SIA 1 (Fig. 1c).

Establishment of rhizopine transkingdom signalling. To demonstrate the potential of rhizopine as a transkingdom signal to bacteria in the rhizosphere, the synthetic pathway was transferred by Agrobacterium rhizogenes-mediated root transformation into Medicago truncatula. SIA was detected in transgenic hairy roots as well as in transgenic root organ cultures of M. truncatula expressing $i d h A$ and mosB under the control of constitutive promoters (Fig. 3a, Supplementary Fig. 11). Medicago truncatula hairy roots were found to produce $27.39 \mathrm{ng} \mathrm{mg}^{-1}$ dry weight SIA [SE $=9.38 ; N=3$ ] (Supplementary Data 1 ) and SIA 1 was exuded into the rhizosphere at sufficient levels for Rlv3841, carrying the rhizopine lux biosensor, to luminesce (Fig. 3c, Supplementary Fig. 11). No luminescence was observed when the rhizopine lux biosensor was inoculated on the transgenic roots constitutively expressing idhA alone that produced scyllo-inosose (Supplementary Fig. 12). This confirmed that rhizopine acts as a transkingdom signal to bacteria, rather than the scyllo-inosose intermediate, in the rhizopine synthetic pathway engineered into plants.

The most important targets for transfer of rhizopine-mediated transkingdom signalling are cereals, where there are large global efforts to engineer plant growth promotion, disease resistance and $\mathrm{N}_{2}$ fixation by bacteria. To assess if we could engineer rhizopine synthesis in cereals, we transferred the rhizopine biosynthesis genes into Hordeum vulgare (barley).

SIA 1 production was observed in transgenic roots of $\mathrm{T}_{0}$ and $\mathrm{T}_{1}$ barley plants by GC-MS analysis (Fig. $3 \mathrm{~b}$ ). $\mathrm{T}_{0}$ and $\mathrm{T}_{1}$ barley plants were found to produce $6.55 \mathrm{ng} \mathrm{mg}^{-1}$ dry weight $[\mathrm{SE}=0.43 ; n=$ 10] and $7.00 \mathrm{ng} \mathrm{mg}^{-1}$ dry weight [SE $=0.17 ; n=10, N=2$ ] of rhizopine in their transgenic roots, respectively (Supplementary Data 2-4). SIA 1 produced in transgenic roots of $\mathrm{T}_{0}$ barley plants acted as a transkingdom signal to bacteria containing the rhizopine lux biosensor (Fig. 3d). As cereals are our intended final target plants and transgenic seed is available for rhizopine secreting barley, we measured the signalling between barley roots and bacteria in the rhizosphere using a green fluorescent protein (GFP) rhizopine biosensor. Confocal images revealed that rhizopine produced in transgenic roots of $\mathrm{T}_{1}$ barley plants induced GFP fluorescence at a significant level in most bacterial colonies carrying the rhizopine GFP biosensor on the root surface (Fig. 4a, b). Thus, a circuit of plant-dependent synthesis and signalling by SIA 1 to bacteria in the rhizosphere has been established. 

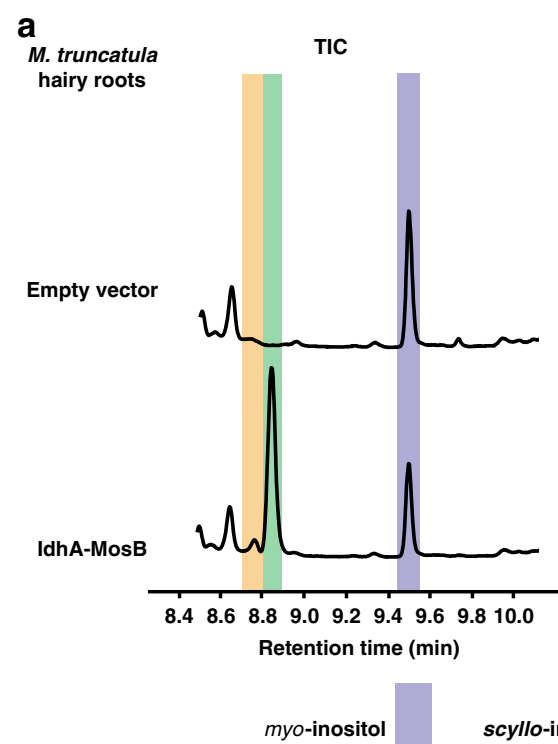

scyllo-inosose

C

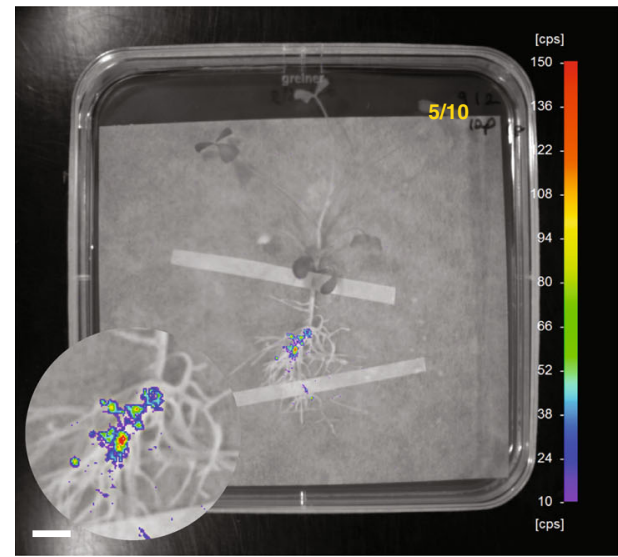

Engineered

d

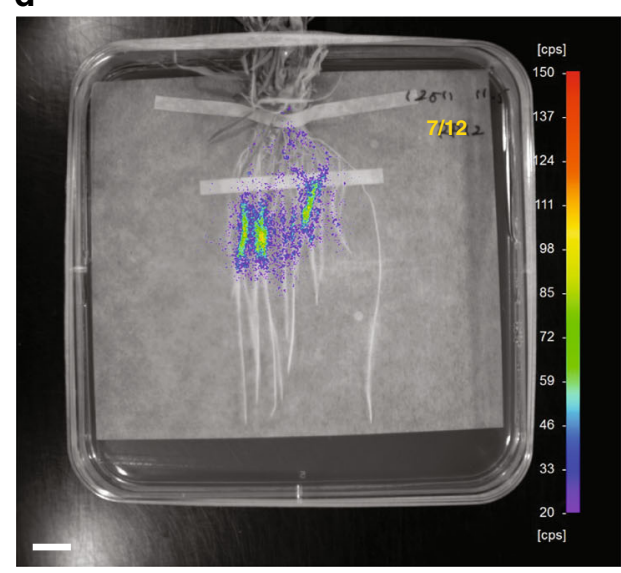

Engineered

\section{Discussion}

The synthetic transkingdom signalling pathway established in this work opens up the microbial pan-genome to plant control. For example, it could activate specific members of the microbiota to fix $\mathrm{N}_{2}$, produce antibiotics or hormones, chelate iron or solubilise soil nutrients ${ }^{31}$. Control of these traits by the host plant would

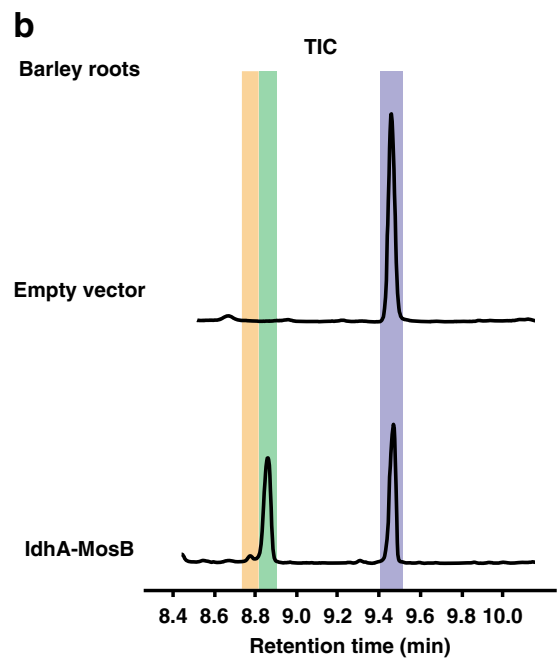

scyllo-inosamine

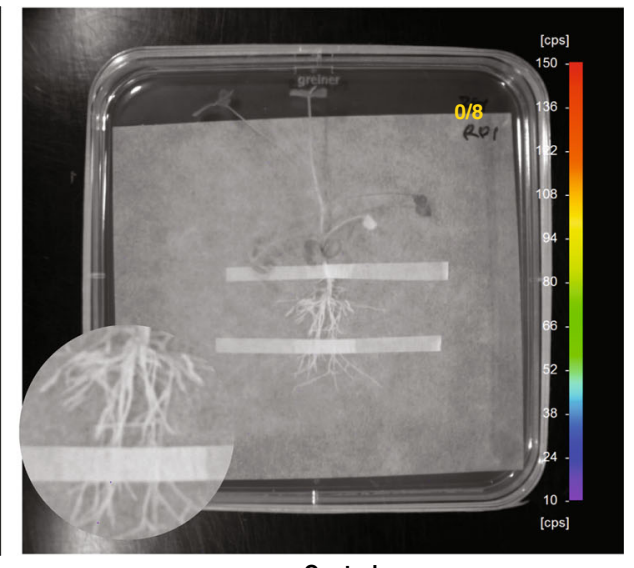

Control

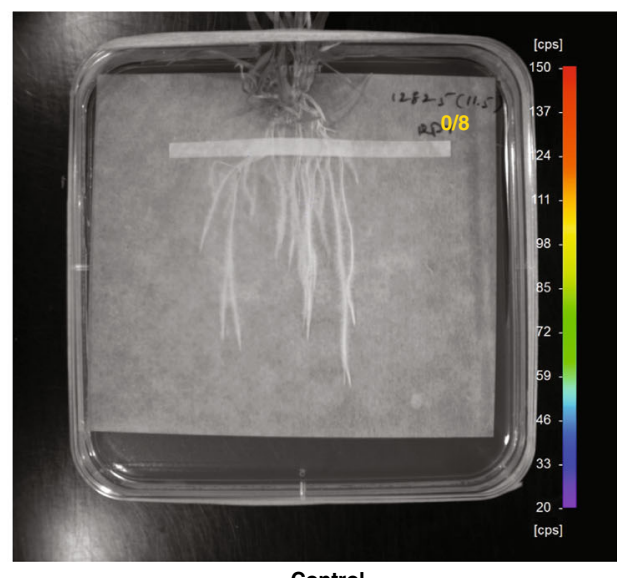

Control

prevent off-target effects in species such as weeds that would be caused by constitutive expression. Furthermore, the inducible expression system we established here will help alleviate growth penalties incurred by constitutive overexpression of energetically intensive plant growth promotion traits in microbes. Finally, escape of genetically modified bacterial inoculants into the 
Fig. 3 Rhizopine biosynthesis and signalling in M. truncatula and barley roots. a, b Gas chromatography-mass spectrometry (GC-MS) total ion chromatograms (TICs) of extracts prepared from $M$. truncatula transgenic roots (a) and transgenic $T_{0}$ barley seedlings (b) transformed with empty vector (control) or IdhA-MosB together. Highlighted peaks indicate scyllo-inosamine 1 (orange), scyllo-inosose $\mathbf{7}$ (green) and myo-inositol 3 (dark blue). All chromatograms are representative of experiments repeated at least three independent times. Source data for GC-MS chromatograms are provided as a Source Data file in Supplementary Materials. c, d NightOwl images showing bioluminescence of Rlv3841/pOPS0046 rhizopine lux biosensor on the surface of $M$. truncatula transgenic roots (c) and $T_{0}$ barley seedlings (d) transformed with empty vector (control) or IdhA-MosB together (engineered). Numbers in top right corners indicate number of plants tested that showed significant levels of bioluminescence (scale bar, $1 \mathrm{~cm}$ ). Colours represent luminescence intensity from 10 or 20 counts per second (cool/purple) to 150 counts per second (warm/red). Source data underlying $\mathbf{a}$, b are provided as a Source Data file

environment could be addressed by integrating plant signal recognition with biocontainment strategies ${ }^{32}$.

A key example requiring host control of a microbe is the aim of transferring $\mathrm{N}_{2}$ fixation to alleviate the demand for chemical fertilizers in agriculture. To achieve this aim, cereals must control $\mathrm{N}_{2}$ fixation by bacteria that grow on either the surface of roots (epiphytes), inside roots (endophytes) or by bacteria that reside in engineered nodules ${ }^{7-9}$. In analogy to natural transkingdom signalling used by legumes to control rhizobial symbioses, rhizopine transkingdom signalling could control synthetic symbioses to deliver nitrogen to cereal crops.

\section{Methods}

Bacterial strains and growth media. Bacterial strains and plasmids used are shown in Supplementary Tables 1 and 2, respectively. Escherichia coli strains were grown at $37^{\circ} \mathrm{C}$ in Luria-Bertani (LB) medium ${ }^{33}$ with antibiotics: ampicillin $\left(100 \mu \mathrm{g} \mathrm{ml}^{-1}\right)$, tetracycline $\left(10 \mu \mathrm{g} \mathrm{ml}^{-1}\right)$, gentamicin $\left(10 \mu \mathrm{g} \mathrm{ml}^{-1}\right)$, or kanamycin $20 \mu \mathrm{g} \mathrm{ml}^{-1}$ ). Rhizobium leguminosarum and Sinorhizobium meliloti strains were grown in tryptone yeast (TY) medium ${ }^{34}$ or universal minimal salts (UMS) ${ }^{20}$ at $28^{\circ} \mathrm{C}$. Antibiotics added to TY included streptomycin $\left(500 \mu \mathrm{g} \mathrm{ml}^{-1}\right)$, tetracycline $\left(5 \mu \mathrm{g} \mathrm{ml}^{-1}\right)$ and gentamicin $\left(20 \mu \mathrm{g} \mathrm{ml}^{-1}\right)$ for $R$. leguminosarum, and streptomycin $\left(200 \mu \mathrm{g} \mathrm{ml}^{-1}\right)$ or neomycin $\left(80 \mu \mathrm{g} \mathrm{ml}^{-1}\right.$ for plasmids or $200 \mu \mathrm{g} \mathrm{ml}^{-1}$ for pK19 mutants) for $S$. meliloti. Agrobacterium tumefaciens and A. rhizogenes were cultured in LB medium at $28{ }^{\circ} \mathrm{C}$ with antibiotics: rifampicin $\left(50 \mu \mathrm{g} \mathrm{ml}^{-1}\right)$, gentamycin $\left(40 \mu \mathrm{g} \mathrm{ml}^{-1}\right)$, tetracycline $\left(5 \mu \mathrm{g} \mathrm{ml}^{-1}\right)$ or kanamycin $\left(25 \mu \mathrm{g} \mathrm{ml}^{-1}\right)$ for A. tumefaciens, and rifampicin $\left(20 \mu \mathrm{g} \mathrm{ml}^{-1}\right)$, kanamycin $\left(20 \mu \mathrm{g} \mathrm{ml}^{-1}\right)$ or carbenicillin $\left(50 \mu \mathrm{g} \mathrm{ml}^{-1}\right)$ for $A$. rhizogenes.

Plant materials and sterilisation. Medicago sativa seeds were sterilised with $95 \%$ ethanol for $45 \mathrm{~min}$ followed by $6 \%$ sodium hypochlorite for $5 \mathrm{~min}$, and germinated on distilled water agar in the dark for 2 days at room temperature. Pisium sativum seeds were sterilized with $70 \%$ ethanol for $1 \mathrm{~min}$, washed with water, and then with $2 \%$ sodium hypochlorite for $5 \mathrm{~min}$, rinsed thoroughly and germinated on distilled water agar in the dark for 2 days at room temperature. Medicago truncatula ecotype Jester was used for A. rhizogenes transformation. Seeds were scarified with sand paper, sterilised in $1 \%$ sodium hypochlorite for $3 \mathrm{~min}$, incubated on agar (1.5\%) in the dark for 3 days at $4{ }^{\circ} \mathrm{C}$ for stratification and then overnight at room temperature for germination. Seed sterilization and germination of spring barley genotype Golden Promise was performed using standard protocols ${ }^{35}$. Briefly, barley seeds were washed in $70 \%$ ethanol for $3 \mathrm{~min}$, sterilised in $5 \%$ sodium hypochlorite for $4 \mathrm{~min}$, incubated on agar $(0.8 \%)$ in the dark for 3 days at $4{ }^{\circ} \mathrm{C}$ for stratification and then 3 days at room temperature for germination.

Bacterial genetic manipulations and plasmid construction. PCR was performed with Phusion High-Fidelity DNA Polymerase (Thermo Fisher Scientific) using primers in Supplementary Table 4. The biosensor pOPS0046 was constructed by restriction/ligation of a $\operatorname{mocRB}$ amplicon from S. meliloti L5-30 ${ }^{36}$ into pIJ11268 26 . Plasmids for pK19 mutant construction (pOPS0243, pOPS0244) were constructed by cloning internal fragments of $S$. meliloti L5-30 mosB and mosD into pK19mob ${ }^{37}$ by BD In-Fusion cloning (Clontech). The plasmid for IolG purification (pOPS0241) was constructed by BD cloning of Bacillus subtilis iolG into pOPINF ${ }^{38}$.

The plasmid for nodule expression of mosDEF (pOPS0362) was constructed using Saccharomyces cerevisiae homologous recombination ${ }^{39}$. A modified version of the Gram-negative expression vector pMQ $131^{40}$ that contained the par locus for stability in the environment was used for recombineering with PmosB and mosDEF amplicons from S. meliloti L5-30.

The plasmid pOPS0363 used for MosB purification was assembled by golden gate cloning ${ }^{41-43}$. Sinorhizobium meliloti tauR/Ptau taurine promoter, HIS-tagged maltose-binding protein, E. coli codon optimised $\operatorname{mos} B$ and $\operatorname{rrnBT} 1$ terminator were assembled in linear order into pOGG02444.

The rhizopine GFP biosensor plasmid pOPS0761 was constructed by assembly of the mocRB amplicon from pOPS0046 with an amplicon containing the GFPmut3 open reading frame into the modified PMQ131 vector described above by S. cerevisiae homologous recombination ${ }^{39}$. The resulting plasmid was conjugated into Rlv3841::mTn7-mCherry (Rlv3841 containing constitutively expressed mCherry introduced into the genome with pUC18T-miniTn7T-Gm ${ }^{45,46}$ ).

All plasmids were verified by restriction digest and DNA sequencing. Plasmids were transferred by conjugation into rhizobia by tri-parental mating with pRK $2013^{47}$.

Generation of constructs for plant engineering. Constructs for plant engineering were assembled using golden gate cloning ${ }^{41-43}$ (Supplementary Table 3). For transient expression, $R$. leguminosarum idhA and S. meliloti L5-30 mosB were expressed under the control of CaMV 35s promoter (35s) and Lotus japonicus Ubiquitin1 (LjUBI1) promoter, respectively. Sinorhizobium meliloti mosDEF and M. crystallinum IMT were expressed transiently under the control of $35 \mathrm{~s}$ and LjUBI1 promoters, respectively. In barley transgenic lines, $i d h A$ and $\operatorname{mos} B$ were expressed under the control of Zea mays ubiquitin1 promoter and Oryza sativa ubiquitin 1 promoter, respectively. All bacterial genes were codon optimised ${ }^{48}$ for expression in plants. DNA components (promoters, coding sequences and terminators) were synthesised by GeneArt (Life Technologies). Recombinant clones were verified by PCR and DNA sequence analysis. Primers used are listed in Supplementary Table 4.

Bioinformatic identification of rhizopine loci. Putative rhizopine loci were identified by BLAST query of the Joint Genome Institute Integrated Microbial Genomes (IMG) database (https://img.jgi.doe.gov/) with S. meliloti L5-30 MosB and the IMG Ortholog Neighbourhood Viewer tool ${ }^{49}$. Putative rhizopine loci in other bacteria were selected that contained homologues to either mos $C$ or $\operatorname{mos} A$ in addition to $\operatorname{mos} B$. Genetic diagrams of the loci were copied from the IMG website and redrawn with Adobe Illustrator.

Metabolite extraction and GC-MS analysis of root nodules. Growth of $M$. sativa or $P$. sativum plants for nodule extraction was carried out in $1 \mathrm{~L}$ pots filled with sterile vermiculite and nitrogen $\left(\mathrm{N}_{2}\right)$-free rooting solution ${ }^{50}$. Ten germinated $M$. sativa or two germinated $P$. sativum seedlings per pot were inoculated with $1 \times 10^{7}$ colony-forming units (CFUs) of rhizobia in distilled water 3 days after planting. Plants were grown for 6 to 8 weeks before harvesting pink $\mathrm{N}_{2}$-fixing nodules by hand. Pooled nodules from one pot $(<100 \mathrm{mg})$ were ground using a mortar and pestle in liquid nitrogen. Enzymes were inactivated by the addition of $1400 \mu 1100 \%$ methanol and incubated for $10 \mathrm{~min}$ at $70{ }^{\circ} \mathrm{C}$. For metabolite extraction, $750 \mu \mathrm{l}$ of $\mathrm{CHCl}_{3}$ and $1400 \mu \mathrm{l}$ of $\mathrm{dH}_{2} \mathrm{O}$ was added, samples were vortexed and then centrifuged for $15 \mathrm{~min}$ at a relative centrifugal force (RCF) of 2200 . Aliquots of the supernatant were then dried in a vacuum concentrator prior to derivitization ${ }^{51}$. Samples were derivatised by trimethylsilylation prior to GC-MS analysis by incubation with $25 \mu \mathrm{l}$ of pyridine and $35 \mu \mathrm{l}$ of trimethylsilylimidazole (TMSI) (Sigma 33068 ) for $60 \mathrm{~min}$ at $37^{\circ} \mathrm{C}$ with shaking at $950 \mathrm{RPM}$. GC-MS analysis was performed using the LJS_TMSI protocol at the University of Oxford Department of Plant Sciences (Supplementary Methods). For data generated in Supplementary Fig. 5, GC-MS was performed with the LJS_Golm Stardard protocol (Supplementary Methods)

Protein purification. For purification of IolG and IdhA, pOPS0141 and pOPS0142 were transformed into BL21-competent E. coli (New England Biolabs) and grown overnight in $5 \mathrm{ml} \mathrm{LB}{ }^{A m p}$. The next day, the full volume was subcultured to $50 \mathrm{ml}$ $\mathrm{LB}^{\mathrm{Amp}}$. At $\mathrm{OD}_{600}$ (optical density at $600 \mathrm{~nm}$ ) of $0.5,1 \mathrm{mM}$ isopropyl $\beta$-D-1-thiogalactopyranoside (IPTG) was added. After $3 \mathrm{~h}$ of induction cells were pelleted at $4{ }^{\circ} \mathrm{C}$, frozen with liquid nitrogen and stored at $-80^{\circ} \mathrm{C}$. Cell pellets were thawed on ice, resuspended in $1 \mathrm{ml}$ of HIS-binding buffer and disrupted by ribolyzing. Lysate was clarified by centrifugation at $4{ }^{\circ} \mathrm{C}$. Purification of HIS-tagged proteins from the lysate was performed using a His-Spin Protein Miniprep Kit (Zymo Research).

For purification of MosB, R. leguminosarum 3841 maintaining pOPS0363 was grown on a TY agar slope with antibiotics for 3 days, washed with UMS and used to inoculate six baffled flasks containing $500 \mathrm{ml}$ of UMS (containing $20 \mathrm{mM}$ succinate, $10 \mathrm{mM} \mathrm{NH}_{4} \mathrm{Cl}$ and $10 \mathrm{mM}$ taurine) to $\mathrm{OD}_{600}$ of 0.01 . Cultures were grown until they reached an $\mathrm{OD}_{600}$ of 0.5 , pelleted at $4{ }^{\circ} \mathrm{C}$, frozen in liquid nitrogen 
a

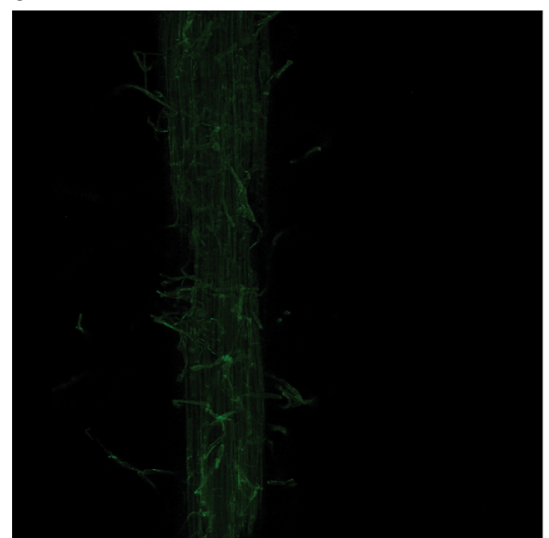

Control

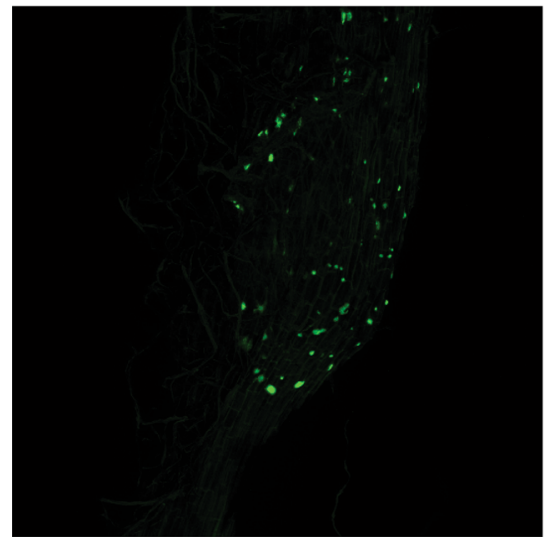

Engineered

b

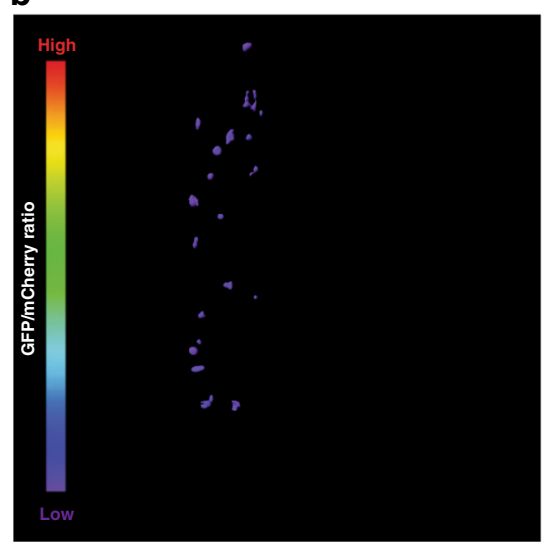

Control

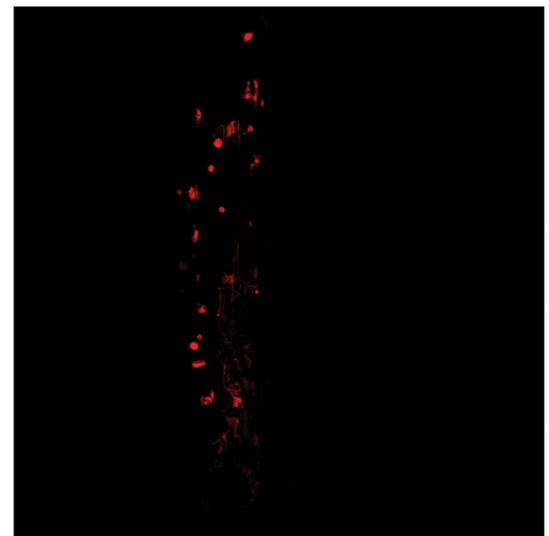

Control

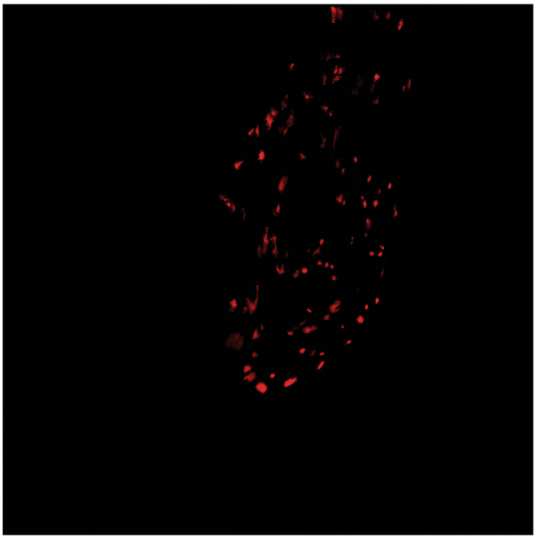

Engineered

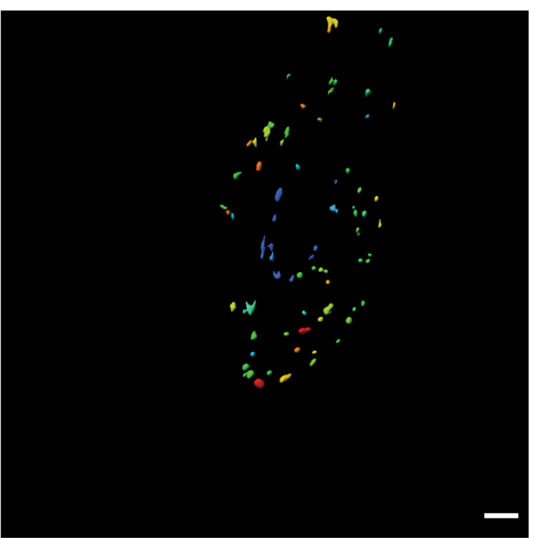

Engineered

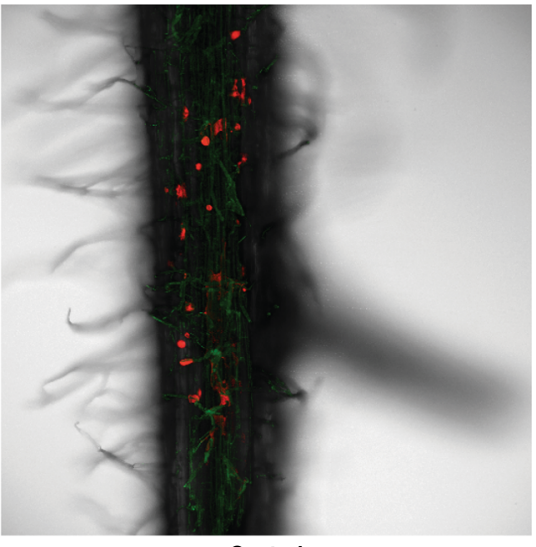

Control

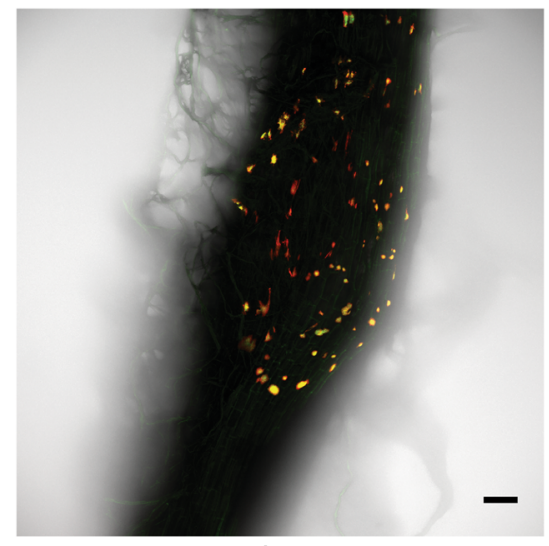

Engineered

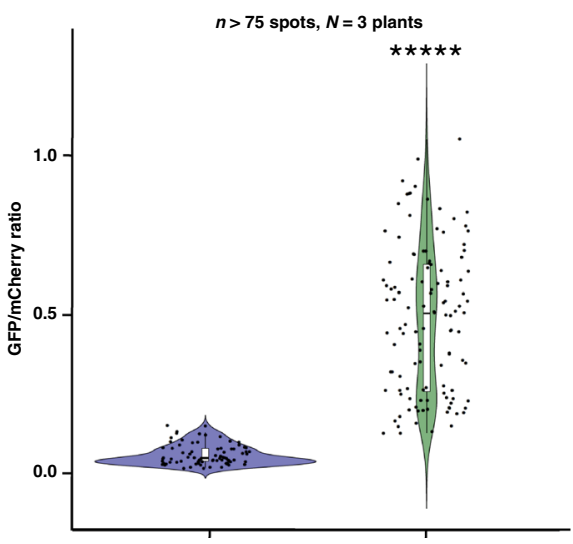

Control

Engineered

Fig. 4 Fluorescent microscopy of rhizopine-mediated transkingdom signalling. a Confocal fluorescence microscopy images showing green fluorescent protein (GFP) fluorescence of Rlv3841::mTn7-mCherry/pOPS0761 biosensor [with constitutive mCherry fluorescence] on the surface of $\mathrm{T}_{1}$ barley seedlings transformed with empty vector (control) or IdhA-MosB together (engineered). Z-stack projections of green fluorescence channel (left, GFP), red fluorescence channel (middle, mCherry) and all channels merged (right, bright-field) are shown (scale bars, $100 \mu \mathrm{m}$ ). Images shown are representative of experiments repeated two independent times. b Three-dimensional images of GFP/mCherry mean intensity ratios in Rlv3841::mTn7-mCherry/pOPS0761 biosensor on the surface of $\mathrm{T}_{1}$ barley seedlings transformed with empty vector (left, control) or IdhA-MosB together (middle, engineered) (scale bars, $100 \mu \mathrm{m}$ ). Cool colours (purple) indicate low GFP/mCherry intensity ratio, and warm colours (red) indicate a high GFP/mCherry intensity ratio. Violin plot of GFP/mCherry ratios in the biosensor colonies (right; $n>75$ spots; $N=3$ plants). Asterisks signify statistical significance (Wilcoxon's signed-rank test, $P=1.30 \times 10^{-14}$ ). Images shown are representative of experiments repeated two independent times

and stored at $-80^{\circ} \mathrm{C}$. Cell pellets were thawed on ice and resuspended in $15 \mathrm{ml}$ extraction buffer (MBPTrap binding buffer $(20 \mathrm{mM}$ Tris- $\mathrm{HCl}, 200 \mathrm{mM} \mathrm{NaCl}$,

$1 \mathrm{mM}$ EDTA, pH 7.4) containing $1 \mathrm{mM}$ dithiothreitol and PMSF Protease Inhibitor (Thermo Fisher)). Cells were disrupted by ribolysing and clarified by centrifugation at $4{ }^{\circ} \mathrm{C}$. The clarified lysate was filtered $(0.45 \mu \mathrm{m})$ and loaded onto a $1 \mathrm{ml}$ MBPTrap HP column on an AKTA Basic 10 (GE Healthcare Life Sciences). The column was washed with running buffer and eluted with running buffer containing $10 \mathrm{mM}$ maltose.

Purity of purified proteins was assessed by sodium dodecyl sulfatepolyacrylamide gel electrophoresis analysis and proteins were quantified using a Qubit 2.0 Fluorometer (Thermo Fisher) according to the manufacturer's instructions. 
MosB in vitro assays. The MosB in vitro assay contained $100 \mathrm{mM}$ Tris- $\mathrm{HCl}, \mathrm{pH}$ 7.5, 0.9 mM PLP, $5 \mathrm{mM}( \pm)-3-O$-methyl-scyllo-inosose $( \pm)-6$ and $5 \mathrm{mM}$ of amino acid and water to a total volume of $100 \mu \mathrm{l}( \pm)$-3-O-methyl-scyllo-inosose $( \pm)$-6 was used immediately following its synthesis due to instabilities observed. The linked assay with IolG used the reaction mixture described above, as well as $5 \mathrm{mM} \mathrm{NAD}^{+}$ and $5 \mathrm{mM}$ myo-inositol 3 as substrate rather than 3-O-methyl-scyllo-inosose. Proteins were added to a concentration of $10 \mu \mathrm{g} \mathrm{ml}^{-1}$. Assays were incubated for $24 \mathrm{~h}$ at $28^{\circ} \mathrm{C}$. Enzyme activity was halted by boiling for $10 \mathrm{~min}$ and protein was removed by centrifugation. The supernatant was dried in a vacuum centrifuge and derivatised by resuspending in $25 \mu \mathrm{l}$ pyridine and $35 \mu \mathrm{TMSI}$ at $37^{\circ} \mathrm{C}$ with shaking for $60 \mathrm{~min}$. GC-MS analysis was performed with the LJS_TMSI protocol at the University of Oxford Department of Plant Sciences (Supplementary Methods).

Transient expression in Nicotiana benthamiana. Recombinant plasmids were mobilised into A. tumefaciens GV3101:pMP90 by electroporation. A transformed single colony was grown in LB with appropriate antibiotics for $24 \mathrm{~h}$, and then subcultured in fresh LB and grown overnight. Cells were harvested by centrifugation and resuspended in infiltration buffer (10 mM MES buffer, pH 5.6, 10 $\mathrm{mM} \mathrm{MgCl} 2$ and $150 \mu \mathrm{M}$ acetosyringone) to an $\mathrm{OD}_{600}$ of 0.5 . After incubating at room temperature in the dark for $3 \mathrm{~h}, A$. tumefaciens strains were mixed with an equal volume of a P19 suppressor strain and infiltrated into the underside of $N$. benthamiana leaves using a needleless $1 \mathrm{ml}$ syringe. Leaf discs were harvested 3 days after infiltration, frozen in liquid nitrogen and the extracted metabolites were analysed by GC-MS.

Hairy-root transformation in Medicago truncatula. Agrobacterium rhizogenes AR1193 was transformed with recombinant constructs by electroporation. A transformed single colony was grown on LB agar plates with antibiotics for $48 \mathrm{~h}$. Cells were removed using sterile toothpicks and suspended in $1 \mathrm{ml}$ of sterile water. Germinated seedlings of $M$. truncatula cultivar Jester were transformed with $A$. rhizogenes AR1193 using standard protocols ${ }^{52}$. Briefly, under sterile conditions cut tip of radicle approximately $3 \mathrm{~mm}$ from the root tip of each germinated seedlings, dip the ends of each cut seedlings into A. rhizogenes AR1193 culture and grown them on ModFP agar plates. Four weeks after transformation, composite plants were screened on the basis of fluorescent enhanced GRP (eGFP) marker. eGFPpositive transgenic roots were harvested and frozen in liquid nitrogen before extracting metabolites for GC-MS analysis.

For cultivation of axenic hairy-root cultures, 4 weeks after transformation of $M$. truncatula seedlings by A. rhizogenes AR1193, transgenic roots of approximately 3 to $5 \mathrm{~cm}$ in length were excised and subcultured every 3 weeks on $M$ agar plates containing $350 \mu \mathrm{g} \mathrm{ml}^{-1}$ of cefotaxime sodium. For GC-MS analysis, 3-week-old transgenic hairy-root organ cultures grown on Modified $\mathrm{M}$ agar plates (containing $0.4 \mathrm{mM} \mathrm{NH}_{4} \mathrm{NO}_{3}$ ) were harvested, frozen in liquid nitrogen and extracted metabolites were analysed.

Stable transformation of Hordeum vulgare. Recombinant binary vectors were transferred by electroporation into A. tumefaciens AGL1 strain. Transformation of barley by recombinant Agrobacterium strains was performed using standard protocols ${ }^{35}$. For rapid testing in $\mathrm{T}_{0}$ barley plants, approximately 12 weeks after transformation, transgenic roots from barley plantlets were harvested, frozen in liquid nitrogen and the extracted metabolites were analysed by GC-MS. Approximately 2 -week-old $\mathrm{T}_{1}$ barley plants were used for confocal microscopy and GC-MS analysis.

GC-MS analysis of engineered plant tissue. Frozen plant materials were lyophilized to dryness, ground to a fine powder and extracted with $70 \%$ ethanol at $70{ }^{\circ} \mathrm{C}$ for $60 \mathrm{~min}$. The resulting extract was centrifuged at an RCF of 15,871 or $10 \mathrm{~min}$ and the supernatant was evaporated to dryness. For GC-MS analysis, dried metabolic samples were dissolved in appropriate volume of $70 \%$ ethanol, $50 \mu \mathrm{l}$ aliquots were dried down and trimethylsilylated using Tri-Sil $\mathrm{Z}$ reagent (Sigma, catalogue no. 92718 ) at $80^{\circ} \mathrm{C}$ for $60 \mathrm{~min}$. GC-MS analysis was performed using the Eng_Plant protocol at the John Innes Centre (Supplementary Methods). Rhizopine production in engineered plant samples were determined using a calibration curve (concentration vs. peak area) drawn by analysing a set of rhizopine standards of known concentrations in GC-MS. MassHunter qualitative analysis software (Agilent) was used to determine the peak area of rhizopine in EIC $(m / z 245)$ chromatograms of the standards and plant samples.

\section{Bacterial luciferase biosensor screening assays. For imaging of rhizopine} synthesis in $M$. sativa sterilised, germinated seedlings were placed onto square plates containing FP-agar overlaid with filter paper. Roots were inoculated at the time of planting with $5 \times 10^{7}$ cells ( $S$. meliloti L5-30 strain and $R$. leguminosarum Rlv3841 carrying the rhizopine lux biosensor mixed 1:1) ${ }^{20}$. Plants were imaged after the formation of $\mathrm{N}_{2}$-fixing nodules at 2 weeks post inoculation.

For imaging rhizopine secretion on transgenic $M$. truncatula hairy roots, 4week-old composite plants with transgenic roots were transferred to new ModFP agar plates and inoculated with Rlv3841 carrying the rhizopine lux biosensor. For transgenic $M$. truncatula root organ cultures, 1-week-old hairy-root explants were transferred to new Modified M agar plates without antibiotics and inoculated with
R. leguminosarum Rlv3841 carrying the rhizopine lux biosensor. Both transgenic $M$. truncatula hairy roots and root organ cultures were imaged every week post inoculation.

For imaging rhizopines secretion on transgenic $\mathrm{T}_{0}$ barley plant roots, approximately 12 -week-old primary $\mathrm{T}_{0}$ barley transformants with strong root growth were transferred from regeneration medium to ModFP agar petridishes without antibiotics and $R$. leguminosarum Rlv3841 carrying the rhizopine lux biosensor was inoculated on the engineered roots. Plants were imaged each day post-inoculation.

Bioluminescence images were analysed for quantification using imaging software IndiGO (Berthold Technologies) and data were expressed as the ratio of

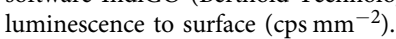

Confocal microscopy and image analysis. For imaging rhizopine-mediated signalling on transgenic $\mathrm{T}_{1}$ barley plant roots, 3-day-old germinated seedlings were grown in ModFP agar Petri dishes and Rlv3841 strain carrying the rhizopine GFPmCherry biosensor was inoculated on the engineered roots. Plants were imaged from 10 days post inoculation.

Confocal images were taken using a Leica SP8-FLIMan with an HC PLAN APO $\times 10 / 0.40$ dry objective. The 488 and $552 \mathrm{~nm}$ lasers were used to excite GFP and red fluorescent protein (mCherry), respectively. Fluorescence emissions were collected using HyD SMD detectors set to detect GFP (500-530 nm) and mCherry $(600-630 \mathrm{~nm})$. The 488 and $552 \mathrm{~nm}$ lasers were set at 4 and $2 \%$ with detector gain at 12 and 36 for GFP and mCherry protein fluorescence imaging, respectively. A line average of three was used and $z$-slices were acquired with a step size of $2.41 \mu \mathrm{m}$.

Confocal images were analysed using IMARIS 8.3.1 (Bitplane) and ImageJ software's. Image processing and analysis were done using IMARIS 8.3.1 as previously described ${ }^{53}$. Briefly, mCherry (RFP) channel was used to segment surfaces (i.e. individual bacterial colonies) using the 'surfaces wizard' with background subtraction and thresholding set at default values $11 \mu \mathrm{m}$ and 361 , respectively. Surfaces were false-coloured based on the mean of the masked GFP and mCherry (RFP) channels. IMARIS Xtension 'XT Mean Intensity Ratio' was used to calculate the $\mathrm{GFP} / \mathrm{mCherry}$ intensity ratio of individual surfaces ${ }^{53}$. The mean intensity ratios (GFP/mCherry) was presented in a violin plot drawn by using R-programming. Wilcoxon's signed-rank test analysis was used to test the level of significance.

Analysis of growth and bioreporter expression in culture. Analysis of expression of bioreporters in free-living culture was performed with either a FLUOstar OMEGA (Lite) or CLARIOstar plate reader (BMG Labtech). Strains were grown in UMS-defined medium with a starting $\mathrm{OD}_{600}$ of 0.1 . UMS was supplemented with either $30 \mathrm{mM}$ sodium pyruvate as a carbon source or $10 \mathrm{mM} \mathrm{NH}_{4} \mathrm{Cl}$ as a nitrogen source. Cultures were grown and monitored in black 24-well plates clear bottom plates covered with a gas-permeable moisture barrier seal (4titude) at $28^{\circ} \mathrm{C}$ shaking at 500 RPM on the orbital setting. Measurements of luminescence were taken at 30-min intervals. Data are expressed as relative luminescence units calculated from total luminescence per well/ culture density measured by $\mathrm{OD}_{595}$.

Reporting summary. Further information on research design is available in the Nature Research Reporting Summary linked to this article.

\section{Data availability}

Data supporting the findings of this work are available within the paper and its Supplementary Information files. A reporting summary for this Article is available as a Supplementary Information file. The datasets generated and analysed during the current study are available from the corresponding author upon request. The source data underlying Figs. 2a-c, 2e, 2f, 3a and 3b as well as Supplementary Figs. 5b, 7, 8a, 10 and 11a are provided as a Source Data file. The $\mathrm{x}$-ray crystallographic coordinates for 1D-19 and $1 \mathrm{~L}-19$ reported in this study have been deposited at the Cambridge Crystallographic Data Centre (CCDC) under deposition numbers CCDC 1919781 [https://www.ccdc.cam. ac.uk/structures/Search?Ccdcid $=$ CCDC\%201919781\&DatabaseToSearch $=$ Published, https://doi.org/10.5517/ccdc.csd.cc22fpfn] and CCDC 1919782 [https://www.ccdc.cam. ac.uk/structures/Search?Ccdcid=CCDC\%201919782a\&DatabaseToSearch=Published, https://doi.org/10.5517/ccdc.csd.cc22fpgp], respectively. These data can be obtained free of charge from The Cambridge Crystallographic Data Centre via www.ccdc.cam.ac.uk/ data_request/cif.

Received: 6 November 2018 Accepted: 7 June 2019 Published online: 31 July 2019

\section{References}

1. Mendes, R. et al. Deciphering the rhizosphere microbiome for diseasesuppressive bacteria. Science 332, 1097-1100 (2011). 
2. Tkacz, A. \& Poole, P. Role of root microbiota in plant productivity. J. Exp. Bot. 66, 2167-2175 (2015).

3. Lundberg, D. S. et al. Defining the core Arabidopsis thaliana root microbiome. Nature 488, 86-90 (2012).

4. Bai, Y. et al. Functional overlap of the Arabidopsis leaf and root microbiota. Nature 528, 364-369 (2015).

5. Castrillo, G. et al. Root microbiota drive direct integration of phosphate stress and immunity. Nature 543, 513-518 (2017).

6. Bageshwar, U. K. et al. An environment friendly engineered Azotobacter can replace substantial amount of urea fertilizer and yet sustain same wheat yield. Appl. Environ. Microbiol. 83, e00590-17 (2017).

7. Fox, A. R. et al. Major cereal crops benefit from biological nitrogen fixation when inoculated with the nitrogen-fixing bacterium Pseudomonas protegens Pf-5 X940. Environ. Microbiol. 18, 3522-3534 (2016).

8. Geddes, B. A. et al. Use of plant colonizing bacteria as chassis for transfer of $\mathrm{N}_{2}$-fixation to cereals. Curr. Opin. Biotechnol. 32, 216-222 (2015).

9. Pankievicz, V. et al. Robust biological nitrogen fixation in a model grass-bacterial association. Plant J. 81, 907-919 (2015).

10. Mondy, S. et al. An increasing opine carbon bias in artificial exudation systems and genetically modified plant rhizospheres leads to an increasing reshaping of bacterial populations. Mol. Ecol. 23, 4846-4861 (2014).

11. Savka, M. A. \& Farrand, S. K. Modification of rhizobacterial populations by engineering bacterium utilization of a novel plant-produced resource. Nat. Biotechnol. 15, 363-368 (1997).

12. Oger, P., Petit, A. \& Dessaux, Y. Genetically engineered plants producing opines alter their biological environment. Nat. Biotechnol. 15, 369-372 (1997).

13. Savka, M. A. et al. The "biased rhizosphere" concept and advances in the omics era to study bacterial competitiveness and persistence in the phytosphere. Molecular Microbial Ecology of the Rhizosphere. 1, 1145-1161 (2013).

14. Murphy, P. J., Wexler, W., Grzemski, W., Rao, J. P. \& Gordon, D. Rhizopines -their role in symbiosis and competition. Soil Biol. Biochem. 27, 525-529 (1995).

15. Wexler, M., Gordon, D. \& Murphy, P. J. The distribution of inositol rhizopine genes in Rhizobium populations. Soil Biol. Biochem. 27, 531-537 (1995).

16. Murphy, P. J., Trenz, S. P., Grzemski, W., De Bruijn, F. J. \& Schell, J. The Rhizobium meliloti rhizopine mos locus is a mosaic structure facilitating its symbiotic regulation. J. Bacteriol. 175, 5193-5204 (1993).

17. Murphy, P. J. et al. Genes for the catabolism and synthesis of an opine-like compound in Rhizobium meliloti are closely linked and on the Sym plasmid. Proc. Natl Acad. Sci. USA 84, 493-497 (1987).

18. Gordon, D. M., Ryder, M. H., Heinrich, K. \& Murphy, P. J. An experimental test of the rhizopine concept in Rhizobium meliloti. Appl. Environ. Microbiol. 62, 3991-3996 (1996).

19. Rossbach, S., Kulpa, D. A., Rossbach, U. \& de Bruijn, F. J. Molecular and genetic characterization of the rhizopine catabolism (mocABRC) genes of Rhizobium meliloti L5-30. Mol. Gen. Genet. 245, 11-24 (1994).

20. Pini, F. et al. Lux bacterial biosensors for in vivo spatiotemporal mapping of root secretion. Plant Physiol. 174, 1289-1306 (2017).

21. Krief, A. et al. Elucidation of the absolute configuration of rhizopine by chiral supercritical fluid chromatography and vibrational circular dichroism. J. Sep. Sci. 38, 2545-2550 (2015).

22. Rao, J. P., Grzemski, W. \& Murphy, P. J. Rhizobium meliloti lacking mosA synthesizes the rhizopine scyllo-inosamine in place of 3-O-methyl-scylloinosamine. Microbiology 141, 1683-1690 (1995).

23. Phenix, C. P., Nienaber, K., Tam, P. H., Delbaere, L. T. J. \& Palmer, D. R. J. Structural, functional and calorimetric investigation of MosA, a dihydrodipicolinate synthase from Sinorhizobium meliloti L5-30, does not support involvement in rhizopine biosynthesis. Chembiochem 9, 1591-1602 (2008).

24. Yum, D.-Y., Lee, Y.-P. \& Pan, J.-G. Cloning and expression of a gene cluster encoding three subunits of membrane-bound gluconate dehydrogenase from Erwinia cypripedii ATCC 29267 in Escherichia coli. J. Bacteriol. 179, 6566-6572 (1997).

25. Ramaley, R., Fujita, Y. \& Freese, E. Purification and properties of Bacillus subtilis inositol dehydrogenase. J. Biol. Chem. 254, 7684-7690 (1979).

26. Poole, P. S., Blyth, A., Reid, C. J. \& Walters, K. myo-Inositol catabolism and catabolite regulation in Rhizobium leguminosarum bv. viciae. Microbiology 140, 2787-2795 (1994).

27. Van Straaten, K. E., Zheng, H., Palmer, D. R. J. \& Sanders, D. A. R. Structural investigation of myo-inositol dehydrogenase from Bacillus subtilis: implications for catalytic mechanism and inositol dehydrogenase subfamily classification. Biochem. J. 432, 237-247 (2010).

28. Van Straaten, K. E., Hoffort, A., Palmer, D. R. J. \& Sanders, D. A. R. Purification, crystallization and preliminary X-ray analysis of inositol dehydrogenase (IDH) from Bacillus subtilis. Acta Crystallogr. Sect. F 64, 98-101 (2008).

29. Daniellou, R., Zheng, H., Langill, D. M., Sanders, D. A. R. \& Palmer, D. R. J. Probing the promiscuous active site of myo-inositol dehydrogenase using synthetic substrates, homology modeling, and active site modification. Biochemistry 46, 7469-7477 (2007).

30. Zheng, H., Bertwistle, D., Sanders, D. A. R. \& Palmer, D. R. J. Converting NAD-specific inositol dehydrogenase to an efficient NADP-selective catalyst, with a surprising twist. Biochemistry 52, 5876-5883 (2013).

31. Lugtenberg, B. \& Kamilova, F. Plant-growth-promoting rhizobacteria. Аnnu. Rev. Microbiol. 63, 541-556 (2009).

32. Chan, C. T. Y., Lee, J. W., Cameron, D. E., Bashor, C. J. \& Collins, J. J. 'Deadman' and 'Passcode' microbial kill switches for bacterial containment. Nat. Chem. Biol. 12, 82-86 (2016)

33. Sambrook, J., Fritsch, E. F. \& Maniatis, T. Molecular Cloning: A Laboratory Manual (Cold Spring Harbor Laboratory, Cold Spring Harbor, 1989).

34. Beringer, J. E. R factor transfer in Rhizobium leguminosarum. Microbiology $\mathbf{8 4}$, 188-198 (1974).

35. Harwood, W. A. A protocol for high-throughput Agrobacterium-mediated barley transformation. Methods Mol. Biol. 1099, 251-260 (2014).

36. Frederix, M. et al. Mutation of praR in Rhizobium leguminosarum enhances root biofilms, improving nodulation competitiveness by increased expression of attachment proteins. Mol. Microbiol. 93, 464-478 (2014).

37. Pridmore, R. D. New and versatile cloning vectors with kanamycin-resistance marker. Gene 56, 309-312 (1987)

38. Berrow, N. S., Alderton, D. \& Owens, R. J. The precise engineering of expression vectors using high-throughput In-Fusion ${ }^{\mathrm{TM}}$ PCR cloning. Methods Mol. Biol. 498, 75-90 (2009).

39. Shanks, R. M. Q., Caiazza, N. C., Hinsa, S. M., Toutain, C. M. \& O’Toole, G. A. Saccharomyces cerevisiae-based molecular tool kit for manipulation of genes from Gram-negative bacteria. Appl. Environ. Microbiol. 72, 5027-5036 (2006).

40. Shanks, R. M. Q., Kadouri, D. E., MacEachran, D. P. \& O’Toole, G. A. New yeast recombineering tools for bacteria. Plasmid 62, 88-97 (2009).

41. Weber, E., Engler, C., Gruetzner, R., Werner, S. \& Marillonnet, S. A modular cloning system for standardized assembly of multigene constructs. PLoS ONE 6, e16765 (2011).

42. Engler, C., Kandzia, R. \& Marillonnet, S. A one pot, one step, precision cloning method with high throughput capability. PLoS ONE 3, e3647 (2008)

43. Engler, C., Gruetzner, R., Kandzia, R., Marillonnet, S. \& Duguay, A. Golden gate shuffling: a one-pot DNA shuffling method based on type IIs restriction enzymes. PLoS ONE 4, e5553 (2009).

44. Geddes, B. A., Mendoza-Suárez, M. A. \& Poole, P. S. A bacterial expression vector archive (BEVA) for flexible modular assembly of Golden Gatecompatible vectors. Front. Microbiol. 9, 3345 (2018).

45. Choi, K.-H. \& Schweizer, H. P. mini-Tn7 insertion in bacteria with single att $\mathrm{Tn} 7$ sites: example Pseudomonas aeruginosa. Nat. Protoc. 1, 153-161 (2006).

46. Choi, K.-H. et al. A Tn7-based broad-range bacterial cloning and expression system. Nat. Methods 2, 443-448 (2005).

47. Figurski, D. H. \& Helinski, D. R. Replication of an origin-containing derivative of plasmid RK2 dependent on a plasmid function provided in trans. Proc. Natl. Acad. Sci. USA 76, 1648-1652 (1979).

48. Raab, D., Graf, M., Notka, F., Schödl, T. \& Wagner, R. The GeneOptimizer Algorithm: using a sliding window approach to cope with the vast sequence space in multiparameter DNA sequence optimization. Syst. Synth. Biol. 4, 215-225 (2010).

49. Geddes, B. A., Hausner, G. \& Oresnik, I. J. Phylogenetic analysis of erythritol catabolic loci within the Rhizobiales and Proteobacteria. BMC Microbiol. 13, 46 (2013).

50. Allaway, D. et al. Identification of alanine dehydrogenase and its role in mixed secretion of ammonium and alanine by pea bacteroids. Mol. Microbiol. 36 508-515 (2000).

51. Lisec, J., Schauer, N., Kopka, J., Willmitzer, L. \& Fernie, A. R. Gas chromatography mass spectrometry-based metabolite profiling in plants. Nat. Protoc. 1, 387-396 (2006)

52. Boisson-Dernier, A. et al. Agrobacterium rhizogenes-transformed roots of Medicago truncatula for the study of nitrogen-fixing and endomycorrhizal symbiotic associations. Mol. Plant-Microbe Interact. 14, 695-700 (2001).

53. Rizza, A., Walia, A., Lanquar, V., Frommer, W. B. \& Jones, A. M. In vivo gibberellin gradients visualized in rapidly elongating tissues. Nat. Plants $\mathbf{3}$, 803-813 (2017).

\section{Acknowledgements}

We thank Ramesha Bheemanahally Thimmappa for assistance with GC-MS analysis (John Innes Centre) as well as Wendy Harwood for transformation of barley (John Innes Centre). We thank Raymond Wightman, Gareth Evans, Jongho Sun and Ankit Walia for assistance with confocal imaging and analysis (Sainsbury Laboratory, Cambridge), as well as Tak Lee for assistance with R programming and data analysis (Sainsbury Laboratory, Cambridge). We also thank Jiorgos Kourelis for the maltose-binding protein golden gate module (University of Oxford Department of Plant Sciences). This work was supported by the Biotechnology and Biological Sciences Research Council (grant number BB/L011484/1) and 
the Engineering and Physical Sciences Research Council (grant number EP/L016494/1). S.J.C. and A.J. thank AstraZeneca and the EPSRC for the provision of an Industrial CASE studentship (EP/L505584/1), and the award of Doctoral Prize scheme funding (EP/ N509711/1). S.J.C. thanks St. Hugh's College, Oxford, for research support.

\section{Author contributions}

B.A.G, P.P. and A.M.J. performed the experiments. A.L.T. and K.C. collected and analysed the single-crystal X-ray diffraction data. B.J. constructed strains for fluorescent microscopy. P.B. assisted with GC-MS analysis. The chemical synthesis was supervised by S.J.C. The bacterial genetics and biochemistry was supervised by P.S.P. The plant engineering was supervised by G.E.D.O. Experiments were conceived by B.A.G, P.P., A.J., S.J.C., G.E.D.O. and P.S.P. All authors wrote the manuscript.

\section{Additional information}

Supplementary Information accompanies this paper at https://doi.org/10.1038/s41467019-10882-x.

Competing interests: The authors declare no competing interests.

Reprints and permission information is available online at http://npg.nature.com/ reprintsandpermissions/
Peer review information: Nature Communications thanks Yves Dessaux, and the other, anonymous, reviewer(s) for their contribution to the peer review of this work. Peer reviewer reports are available.

Publisher's note: Springer Nature remains neutral with regard to jurisdictional claims in published maps and institutional affiliations.

\section{(c) (i)}

Open Access This article is licensed under a Creative Commons Attribution 4.0 International License, which permits use, sharing, adaptation, distribution and reproduction in any medium or format, as long as you give appropriate credit to the original author(s) and the source, provide a link to the Creative Commons license, and indicate if changes were made. The images or other third party material in this article are included in the article's Creative Commons license, unless indicated otherwise in a credit line to the material. If material is not included in the article's Creative Commons license and your intended use is not permitted by statutory regulation or exceeds the permitted use, you will need to obtain permission directly from the copyright holder. To view a copy of this license, visit http://creativecommons.org/ licenses/by/4.0/.

(c) The Author(s) 2019 